\title{
Blending of waste biomass for cost-effective chitosan-based biosorbents for removal of reactive dye from aqueous solution
}

\author{
Sok $\mathrm{Kim}^{+}$ \\ Division of Environmental Science \& Ecological Engineering and OJeong Resilience Institute, Korea University, Seoul 02841, Republic of Korea
}

\begin{abstract}
Chitosan (CS) is an attractive natural and biodegradable cationic adsorbent material for treatment of anionic pollutants. For chitosan-based sorbents to be practicable, their price should be low. This study aims at cost reduction of chitosan-based sorbent through making of composite chitosan beads with industrial fermentation waste biomass of Escherichia coli. The maximum biomass content for maintaining stable composite bead structure was approximately $70.4 \%(\mathrm{w} / \mathrm{w})$. The adsorption properties of the bacterial biomass-chitosan composite beads (BCCB) were evaluated using an anionic dye material, Reactive Yellow 2 (RY 2). At $\mathrm{pH} 4$, the maximum uptake of BCCB was $679.13 \pm 23.76 \mathrm{mg} / \mathrm{g}$, whereas those of pristine CS bead (CSB) and raw E. coli biomass were $934.71 \pm 50.97 \mathrm{mg} / \mathrm{g}$ and $200.77 \pm 4.51 \mathrm{mg} / \mathrm{g}$, respectively. However, considering bound amount of RY2 to CS molecules in the CS-based beads, the BCCB showed the 2.1 times higher dye sorption capacity of CS than that of the CS in the CSB. In addition, the cost of RY2 treatment process using BCCB is expected to be shortened by $58 \%$ compared to CSB. Therefore, this study suggests that compositing CS with biomass waste can be a practical way to design cost-effective adsorbents.
\end{abstract}

Keywords: Chitosan, Composite bead, Cost-effective sorbent, E. coli, Immobilization

\section{Introduction}

Dyes are widely distributed commercially for dyeing products in industrial areas such as food, textile, paper, leather, plastic, printing, and cosmetic [1, 2]. Due to their wide industrial application, many industrial fields have discharging dye containing effluents [1]. Dye materials are conceived as one of the most detected pollutants in waterbodies, and they can give negative impacts to water environments, for example interfering the photosynthetic aquatic species by hindering sunlight penetration due to highly optical activity even at low concentration [3, 4]. In addition, some kinds of benzidine- and naphthalene-based dyes have been reported their threats to human health (carcinogenic and mutagenic effects) [5]. Therefore, dyes in effluents should be handled appropriately to maintain human lives and environments.

Biosorption is a promising technology for sequestering ionic materials (dyes, heavy metals and precious metals) contained in effluents. Effluent treatment using biosorption technology has some advantages like cost-effectiveness, easy operation, high efficiency, and biodegradability when compared to conventional techniques
[6, 7]. Diversiform biologically derived materials such as industrial and agricultural wastes [8-10] bacteria [11], algae [12], and biopolymers $[13,14]$ can be applied as a biosorbent because various functional groups which can binding with target ionic pollutants are possessed in the biological materials.

Chitosan (CS) have been considered as ecological biosorbent material due to its biodegradability and non-toxicity $[15,16]$. Adsorption performance of biosorbents for ionic pollutants can be determined by number of binding sites in the sorbent. In the structure of CS, numerous amounts of amino and hydroxyl functional groups are possessed. Therefore, CS has been applied as one of the suitable resources for biosorbent to treat wastewater containing ionic materials such as dyestuffs and precious metals [16]. Uzun [17] applied chitosan powder as a sorbent for removal of reactive dyes (Reactive Yellow 2 and Reactive Black 5, RY2 and RB5) from aqueous solution in neutral pH. Wang et al. [18] tested the cellulose/chitosan composite sorbent for removal Congo Red (CR) from aqueous solution and reported $381.7 \mathrm{mg} / \mathrm{g}$ of CR uptake at $\mathrm{pH} 7$ and $30^{\circ} \mathrm{C}$. In the case of Tao et al. [16], CS was utilized as a coating material of polyacrylonitrile nanofiber (CPNM) via two-step fabrication process, and the prepared CPNM
This is an Open Access article distributed under the terms of the Creative Commons Attribution Non-Commercial License (http://creativecommons.org/licenses/by-nc/3.0/) which permits unrestricted non-commercial use, distribution, and reproduction in any medium, provided the original work is properly cited.

Copyright (C) 2022 Korean Society of Environmental Engineers
Received September 17, 2021 Accepted December 12, 2021

${ }^{\dagger}$ Corresponding author

E-mail: sokkim81@korea.ac.kr

Tel: +90 2223213550

ORCID: 0000-0002-7502-4862 
showed superior sorption uptake $(1,708 \mathrm{mg} / \mathrm{g})$ for Acid Blue-113 dye compared to that of commercial activated carbon $(7.19 \mathrm{mg} / \mathrm{g})$. In addition, Kwak et al. [19] used CS-based sorbent (PEI-modified CS-biomass composite fiber, $\mathrm{PBBF}$ ) for recovery of ruthenium $\mathrm{Ru}$ ) from industrial effluent of Cativa porcess. In addition, the $\mathrm{Ru}$ uptake of PBBF showed the higher value than commercial ion exchange resins. Based on these, it is expectable that the CS-based sorbents can be feasible substitutes for conventional adsorbents such as activated carbons and ion exchange resins. However, international market prices of CS (about 14 20 \$/kg) limit its economic superiority in a practical application. It is important to find a new strategy to reduce the price of CS-bassed sorbents.

The various waste biomasses (especially bacterial wastes) are generated from bio-industrial areas, and it can be recognized as zero-cost biosorbents for various ionic pollutants. In addition, the bacterial biosorbents can be immobilized in the CS matrix by simple process [18]. Through the composition of waste biomass with CS, it can be expected that the price of CS-based sorbent can be reduced as the used amount of CS is reduced in the sorbent manufacture compared to that of pristine CS sorbent. The reduced cost of CS-waste biomass composite sorbent can lead the cost down of adsorption-based water treatment process for ionic pollutants. With this hypothesis, in the present study, industrial waste biomass, Escherichia coli was used as zero cost additives for the CS-based sorbents. The bacterial biomass-CS composite beads (BCCB) composed of different CS content were prepared, and its expectable sorbent price was compared with that of pristine CS beads (CSB). In addition, the sorption performance of the BCCB was compared with that of CSB by several sorption experiments (i.e., pH edge, kinetics, and isotherms) in a batch system. The additive waste $E$. coli biomass reported as adsorbent for anionic dye RY2 due to possessing cationic amine groups $\left(-\mathrm{NH}_{2}\right)$ which can bind anionic materials by electrostatic attraction. In addition, the main binding sites of the CS are cationic amine groups $\left(-\mathrm{NH}_{2}\right)$. Therefore, to determine and compare sorption performance of BCCB and CSB, the anionic dyestuff RY2 was chosen as a model pollutant. Based on the RY2 sorption performance and sorbent price of BCCB, the cost of adsorption process was estimated and compared with those of CSB.

\section{Materials and Methods}

\subsection{Materials}

The industrial waste biomass, dried E. coli biomass (powder form) was supplied from Daesang Co. (Kunsan, Korea). The raw E. coli biomass was washed using $1 \mathrm{M} \mathrm{HCl}$ solution for a day in order to remove remaining pollutants such as impurities and nutrient salts, and to protonate the biomass surface. The protonated E. coli was washed via distilled water for 3 times and freeze-dried for 24 h. The CS material (degree of deacetylation: 75 85\%) was offered in powder form from SHOWA Co. (Tokyo, Japan) and was used without any modifications. The model anionic dye, RY2 (Cibacron Brilliant Yellow 3G-P, $\mathrm{C}_{25} \mathrm{H}_{19} \mathrm{Cl}_{3} \mathrm{~N}_{9} \mathrm{NaO}_{10} \mathrm{~S}_{3}$, MW: 831.02, dye content: $60-70 \%$, and $\left.\lambda_{\max }: 404 \mathrm{~nm}\right)$ and epichlorohydrin $(\mathrm{ECH}, 99 \%<$ ) were obtained from Sigma-Aldrich Ltd. (Korea). HCl (35 37\%) and $\mathrm{NaOH}(97 \%<)$ were purchased from Samchun Chemicals Co. Ltd (Korea) and Daejung Chemicals \& Metals Co., Ltd (Korea), respectively.

\subsection{Preparation of Adsorbents}

CS powder ( $35 \mathrm{~g}$ ) was mixed in $5 \% \mathrm{w} / \mathrm{w}$ acetic acid solution (475 g) and stirred at 300 400 rpm for approximately $12 \mathrm{~h}$ to obtain uniform CS solution. The prepared CS solution (7\% w/w) was left to stand for some time in order to remove air bubbles. The E. coli was mixed with CS solution for biomass-CS suspensions with different biomass:CS ratio to fabricate biomass composite CS beads (BCCB). However, at a ratio exceeding 7:3 of biomass:CS, the viscosity of the mixture was too high to fabricate BCCB. In addition, as mentioned in introduction, by maximizing the biomass content of biomass-CS composite sorbent, the used amount of CS can be reduced, and price of the sorbent can be decreased accordingly. Therefore, the E. coli biomass content for BCCB was chosen $70 \%$ which the highest biomass ratio can make sorbent as a bead type in this study. To prepare BCCB containing biomass content $70 \%$, the $E$. coli biomass ( $3 \mathrm{~g}$ ) was mixed in $18 \mathrm{~g}$ of $7 \%$ CS solution for $10 \mathrm{~h}$. The biomass-CS mixture was dropped into $500 \mathrm{~mL}$ of $1 \mathrm{M} \mathrm{NaOH}$ solution to form beads by using a $300 \mu \mathrm{m}$ inner-diameter needle tip. The BCCB were thoroughly washed with distilled water, then $10 \mathrm{~g}_{\text {wet }}$ of BCCB were cross-linked in $1 \mathrm{M} \mathrm{NaOH}$ solution $(100 \mathrm{~mL})$ containing $2 \mathrm{~mL}$ of ECH. The cross-linking reaction conducted for $30 \mathrm{~min}$ at room temperature $\left(25^{\circ} \mathrm{C}\right)$. Afterward, the cross-linked BCCB were washed for several times via distilled water and freeze dried. The pristine CS beads (CSB) were prepared by dropping $7 \% \mathrm{w} / \mathrm{w}$ CS solution in $1 \mathrm{M} \mathrm{NaOH}$ solution. Thereafter, CSB were cross-linked by the same procedure as that of BCCB. The dried CS-based beads showed approximately 1.5 2 $\mathrm{mm}$ of bead sizes.

\subsection{Batch Sorption Experiments}

The RY2 sorption performances of $E$. coli biomass, CSB and BCCB were evaluated in a batch system. To determine the $\mathrm{pH}$ effect on sorption performance, $\mathrm{pH}$ edge experiments were performed. For this, $0.03 \mathrm{~g}$ of E. coli biomass, CSB and BCCB were each mixed in $30 \mathrm{~mL}$ of $\mathrm{RY} 2$ solution in conical tubes. The initial concentrations of RY2 solutions for $\mathrm{pH}$ edge tests using E. coli and CS-based beads were fixed at 335 and 1,313 mg/L, respectively. To evaluate the maximum sorption capacities $\left(\mathrm{q}_{\mathrm{m}}\right)$ of sorbent, isotherm experiments were performed. For this, $0.03 \mathrm{~g}$ of sorbents were agitated in the $30 \mathrm{~mL}$ of RY2 solution which have different initial concentrations $(0 \sim 1,313 \mathrm{mg} / \mathrm{L})$. During the experiments, the solution $\mathrm{pH}$ of samples was controlled to the desired $\mathrm{pH}$ ranges by using $1 \mathrm{M}$ $\mathrm{NaOH}$ and $1 \mathrm{M} \mathrm{HCl}$ solutions (pH effect: $\mathrm{pH} 2 \sim 11$, isotherm: $\mathrm{pH}$ $3.95 \sim 4.05$ ( $\mathrm{pH} 4)$ ). The samples were agitated for about $96 \mathrm{~h}$ in an auto-shaker at $140 \mathrm{rpm}$ and $25^{\circ} \mathrm{C}$. For kinetic experiment for RY2 adsorption, 0.1g of CSB and BCCB was continuously mixed into the $100 \mathrm{~mL}$ of RY2 solution (initial concentration: 2,021 mg/L, initial pH: $\mathrm{pH} 4$ ) at $200 \mathrm{rpm}$ by magnetic stirring. After then, the solution $\mathrm{pH}$ was continuously monitored and maintained as $\mathrm{pH}$ 4 using $1 \mathrm{M} \mathrm{NaOH}$ and $\mathrm{HCl}$ solutions for approximately 92 hours. During kinetic experiment, RY2 solution samples were taken at 
different adsorption time. To measure remaining RY2 concentration of adsorption experimental samples, the samples were liquid-solid separated by centrifugation at 9,000 rpm. The RY2 concentration in the separated supernatants was measured using a UV spectrophotometer (UV-2550, Shimadzu, Kyoto, Japan) at $404 \mathrm{~nm}$. The RY2 uptakes of applied sorbents were calculated using the following mass balance equation:

$$
q=\left(V_{i} C_{i}-V_{f} C_{f}\right) / M
$$

where $\mathrm{q}(\mathrm{mg} / \mathrm{g})$ is RY2 uptakes of sorbents. V (L) and C (mg/L) are experimental volume and concentration of RY2, respectively. The subscripts $i$ and $f$ indicate the initial and final state, respectively. The final volume is calculated as sum of the initial volume and added volume of acid and/or base solution for $\mathrm{pH}$ control. M (g) is the mass of the adsorbents.

In addition, RY2 recovery rate could be calculated by the following equation.

$$
R Y 2 \text { recovery rate }(\%)=
$$

(Desorbed RY2 amount $(\mathrm{mg}) /$ Adsorbed $R Y 2$ amount $(\mathrm{mg})) \times 100$

\subsection{Fourier Transform Infrared Spectrometer Analysis}

To compare functional group properties of E. coli biomass, CSB, and BCCB, the infrared spectra properties of the sorbents were obtained from Fourier transform infrared spectrometer (FT/IR-4100, Jasco, Japan). The FT-IR analyses were conducted using KBr-sorbent pallets The FT-IR spectrum of each sample was measured in the wavelength range of $700-4,000 \mathrm{~cm}^{1}$.

\subsection{Scanning Electron Microscope (SEM) Observation of Sorbents}

To compare morphological properties of CSB and BCCB, the SEM observation was conducted. Before SEM observation, the surface of CSB and BCCB were coated by platinum (Pt) in a vacuum chamber for 2 mins (8 $\mathrm{nm}$ coating). Then, the Pt-coated CSB and BCCB were analysis using an SEM instrument (Field emission scanning electron microscope, JEOL-7610F-Plus, Japan) at $\times 40$ magnification.

\section{Results and Discussion}

\subsection{Comparison of Functional Groups Property of the Sorbents}

The functional groups property of a sorbent is an important factor to confirm biosorption performance of biosorbents. Therefore, the FT-IR analysis of E. coli biomass, CSB, and BCCB were carried out to determine properties of their functional groups. The observed FT-IR spectra of sorbents are displayed in Fig. 1.

The FT-IR spectrum of the E. coli biomass in Fig. 1(a) showed various FT-IR peaks at 3,600 3,200, and around 2,925, 1,735, 1,645, $1,538,1,453,1,408,1,233$, and $1,075 \mathrm{~cm}^{-1}$, which representing different kinds of functional groups on the surface of the biomass. Adsorption peaks in range of 3,600 3,200 $\mathrm{cm}^{-1}$ indicate the $\mathrm{O}-\mathrm{H}$ of hydroxyl group and $\mathrm{N}-\mathrm{H}$ asymmetric stretching of the amines on the E. coli biomass [20, 21]. The peaks at around $2,925 \mathrm{~cm}^{-1}$ are characteristic often seen due to presence of the $-\mathrm{CH}_{2}$ and $-\mathrm{CH}_{3}$ [22].

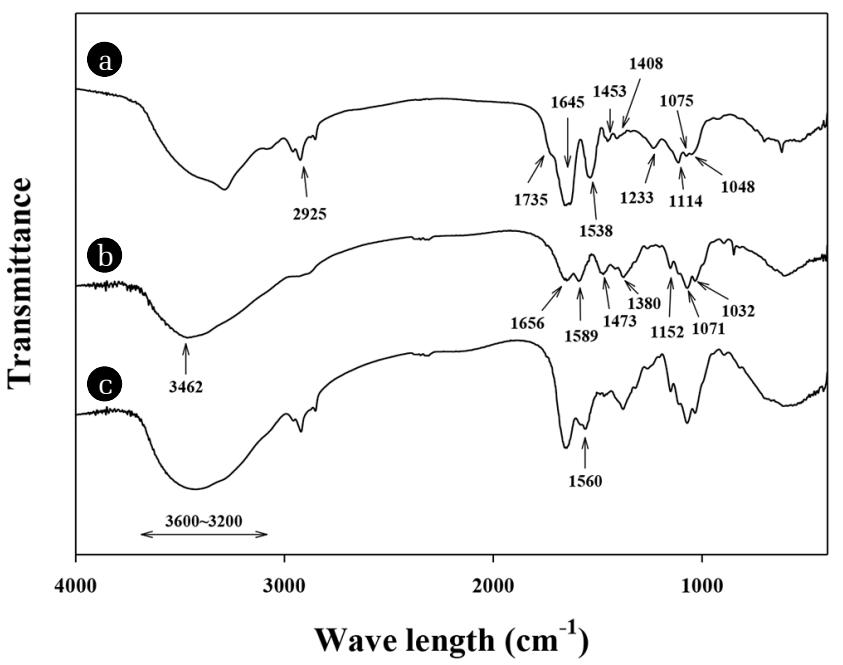

Fig. 1. FT-IR spectrum of (a) the E. coli biomass, (b) the chitosan and (c) the chitosan/E. coli biomass composite bead.

The peak at $1,735 \mathrm{~cm}^{-1}$ indicates carbonyl stretching of un-ionized carboxylates $[23,24]$. The strong peak at $1,645 \mathrm{~cm}^{-1}$ are associated with the carboxyl groups on the surface of E. coli biomass [25]. The peak at $1,538 \mathrm{~cm}^{-1}$ might attributed to the amide I and the carboxyl group ( $\mathrm{C}=\mathrm{O}$ chelate stretching) and amide II bonds [26, 27]. The peaks at 1,453 and $1,408 \mathrm{~cm}^{-1}$ indicate the alkanes [28] and symmetrical stretching of carboxylic acids, respectively [29]. The peak at $1,233 \mathrm{~cm}^{-1}$ indicate $\mathrm{C}-\mathrm{O}$ stretching of the carboxyl groups [30]. In addition, the phosphonate group (P-OH stretching) of the E. coli biomass could be identified by the $1,075 \mathrm{~cm}^{-1}$ peak [31]. In case of CS bead, shown in Fig. 1(b), the main spectrum peaks were obtained at around 3,462, 1,656, 1,589, 1,473, 1,380, $1,152,1,071$, and $1,032 \mathrm{~cm}^{-1}$. The strong and broad band at around $3,462 \mathrm{~cm}^{-1}$ corresponds to the $\mathrm{N}-\mathrm{H}$ and $\mathrm{O}-\mathrm{H}$ stretching vibrations of chitosan [32]. The peak at $1,656 \mathrm{~cm}^{-1}$ is attributed to the secondary amide $\mathrm{C}=\mathrm{O}$ bond that is contributed by the acetamide groups [33]. The peaks observed at 1,589 and $1,473 \mathrm{~cm}^{-1}$ are attributed to $-\mathrm{NH}$ bending vibration in $-\mathrm{NH}_{2}$ and $-\mathrm{NH}$ deformation vibration, respectively [34, 35]. The peak at $1,380 \mathrm{~cm}^{-1}$ indicates aliphatic C-H stretching [36]. The peak at $1,152 \mathrm{~cm}^{-1}$ is due to $-\mathrm{CN}$ stretching vibration [37]. Meanwhile, the peaks at 1,071 and $1,032 \mathrm{~cm}^{-1}$ are due to the -CO stretching in $\mathrm{COH}[37,38]$. The FT-IR spectrum of BCCB showed the characteristic of $E$. coli biomass and CS, because BCCB is a composite of them (Fig. 1(c)). From FTIR spectrum of BCCB, the peak at $3,200 \mathrm{~cm}^{-1}$, which is typical of CS, was enhanced after compositing CS with $E$. coli biomass. In addition, a joint peak emanating from the biomass $\left(1,538 \mathrm{~cm}^{-1}\right)$ and $\mathrm{CS}\left(1,589 \mathrm{~cm}^{-1}\right)$ was observed at $1,560 \mathrm{~cm}^{-1}$, and may indicate $-\mathrm{NH}$ bending vibration in $-\mathrm{NH}_{2}$.

\section{2. $\mathrm{pH}$ Dependence of Sorbents on RY2 Adsorption}

As a result of $\mathrm{pH}$ effect (Fig. 2), the RY2 sorption capacities of E. coli biomass, CSB and BCCB were highly affected by solution $\mathrm{pH}$. As the $\mathrm{pH}$ increased, significant decreasing of RY2 sorption capacity of $E$. coli biomass was shown until around $\mathrm{pH} 6$ and finally reached zero above $\mathrm{pH}$ 7. From the FT-IR analyses, possession 


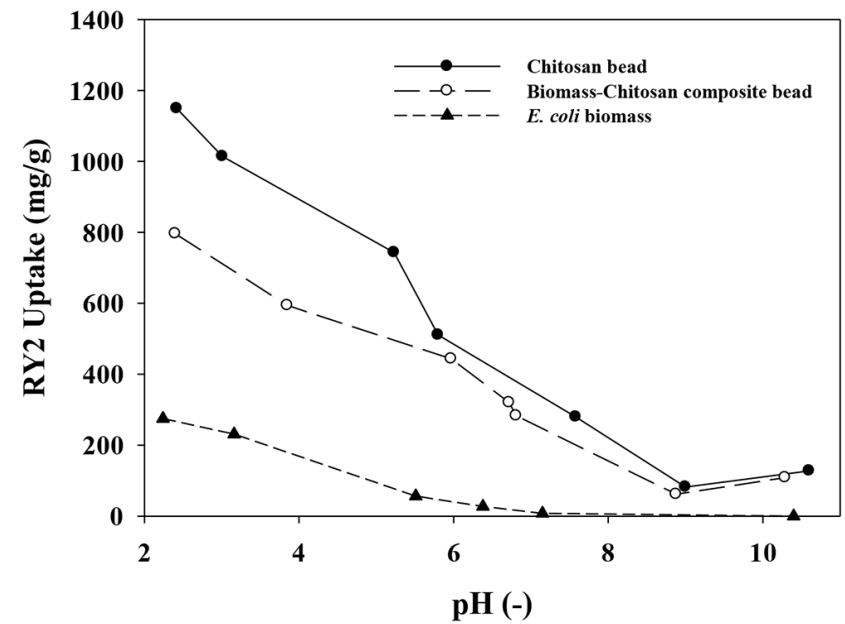

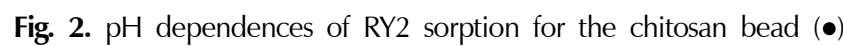
and the chitosan/biomass composite bead (०). Sorbent densities was $1 \mathrm{~g} / \mathrm{L}$. The initial concentrations of RY2 solutions for $\mathrm{pH}$ edge tests using E. coli and CS-based beads were $335 \mathrm{mg} / \mathrm{L}$ and $1,313 \mathrm{mg} / \mathrm{L}$, respectively.

of various anionic and cationic functional groups (carboxyl, phosphonate, and amine groups) on the $E$. coli biomass were confirmed. The amine groups on the biomass can be protonated and positively charged $\left(-\mathrm{NH}_{3}{ }^{+}\right)$at $\mathrm{pH}$ less than their $\mathrm{pK}_{\mathrm{a}}$ values $\left(\mathrm{pK}_{\mathrm{a}}\right.$ 8 11) [39]. Therefore, the negatively charged RY2 molecules in aqueous solution can be bound to amine groups at low $\mathrm{pH}$ by electrostatic attraction between positive amine groups and negative RY2 molecules. On the contrary, the $\mathrm{pK}_{\mathrm{a}}$ values of carboxyl groups and phosphonate groups on the biomaterials are between 3.5 5.0 [40] and 6.1 6.8, respectively [39, 41]. Thus, the carboxyl and phosphonate groups are changed into negative charges by deprotonation of functional groups with increasing $\mathrm{pH}$. The negatively charged functional groups can interrupt the adsorption of RY2 ions onto the biomass by electrostatic repulsion. Therefore, the RY2 sorption capacity of E. coli biomass decreased with increasing $\mathrm{pH}$. The $\mathrm{pH}$ effect for RY2 sorption of CSB and BCCB also showed similar $\mathrm{pH}$ dependence like E. coli biomass. The RY2 uptake of CSB was higher than that of BCCB in the range of $\mathrm{pH} 2$ to $\mathrm{pH}$ 6, however the RY2 uptake of CSB and BCCB were similar above $\mathrm{pH}$ 6. The matrix of CSB and BCCB consist of chitosan which has large number of positive amine groups as main functional groups. However, the $\mathrm{pK}_{\mathrm{a}}$ value of amine group in the chitosan structure were reported as 6.4 [42], and the positively charged amine groups $\left(-\mathrm{NH}_{3}{ }^{+}\right)$of CSB and BCCB may significantly lost their positive charges by deprotonation at $\mathrm{pH}$ around 6 , similar to their $\mathrm{pK}_{\mathrm{a}}$ values. Moreover, the performance of BCCB for RY2 was additionally influenced by electrostatic characteristics of the anionic functional groups in the composed E. coli biomass. Hence, the RY2 uptakes of CS-based beads, CSB and BCCB, decreased with increasing $\mathrm{pH}$. Although the RY2 sorption capacity of sorbents can be maximized under acidic condition, the CS-based beads cannot be stable. Therefore, considering the stability of CS-based beads, the subsequent biosorption experiments were conducted at $\mathrm{pH} 4$.

\subsection{Comparison of Maximum Sorption Capacity}

To evaluate the maximum RY2 uptakes of the E. coli biomass, $\mathrm{CSB}$, and BCCB, isotherm experiments were carried out at $\mathrm{pH}$ 4. The CS-based beads were stable at solution $\mathrm{pH} 4$ without CS matrix loss.

As shown in Fig. 3, the RY2 uptakes of sorbents increased with increasing initial concentration of RY2 and reached to the saturated states. To determine detail maximum sorption capacities of sorbents, the Langmuir isotherm equation [43] was applied to the experimental isotherm results of sorbents. The Langmuir isotherm model equation can be presented as follow:

$$
q=q_{m} b C_{e} /\left(1+b C_{e}\right)
$$

where $\mathrm{q}$ is the experimental RY2 sorption capacity of sorbents (mg/g), $\mathrm{C}_{\mathrm{e}}(\mathrm{mg} / \mathrm{L})$ is the RY2 concentration at sorption equilibrium, $\mathrm{q}_{\mathrm{m}}$ is the maximum sorption capacity (mg/g) of sorbent and $\mathrm{b}(\mathrm{L} / \mathrm{mg})$ is a Langmuir constant [44]. The estimated parameters from Langmuir model equation are described in Table 1.

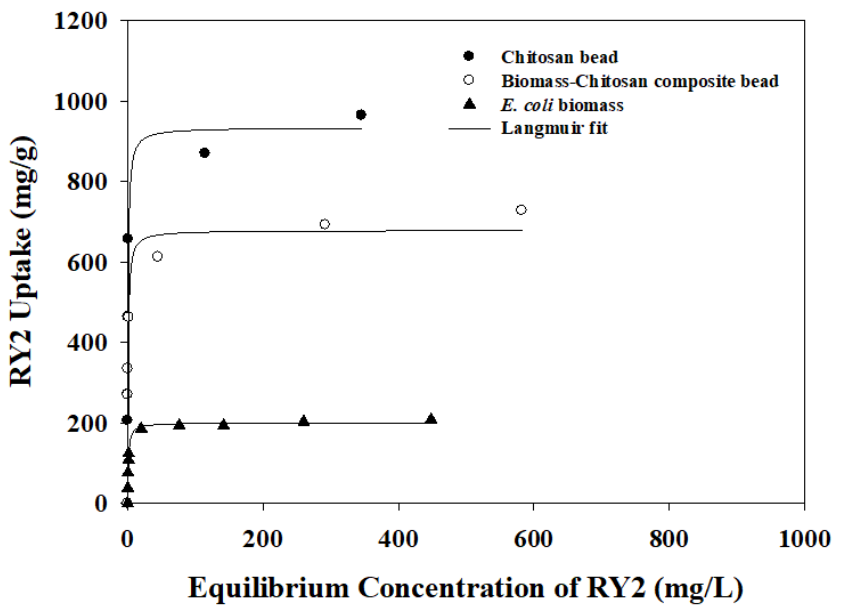

Fig. 3. Isotherm results of the chitosan bead $(\bullet)$, chitosan/biomass composite bead (०) and protonated E. coli $(\mathbf{\Delta})$ biomass for RY2 at $\mathrm{pH} 4$ (Sorbent concentration $=1 \mathrm{~g} / \mathrm{L}$ ).

Table 1. Experimental and Practical Isotherm Parameters of Sorbents that Were Obtained from a Langmuir Model at $\mathrm{pH} 4$

\begin{tabular}{lccc}
\hline \multirow{2}{*}{ Sorbent } & \multicolumn{3}{c}{ Parameters } \\
\cline { 2 - 4 } & $\mathbf{q}_{\mathbf{m}}(\mathbf{m g} / \mathbf{g})$ & $\mathbf{b}(\mathbf{L} / \mathbf{m g})$ & $\mathbf{R}^{\mathbf{2}}$ \\
\hline Experimental view & & & \\
CSB & $934.71 \pm 50.97$ & $1.346 \pm 0.262$ & 0.9664 \\
BCCB & $679.13 \pm 23.76$ & $1.274 \pm 0.219$ & 0.9795 \\
E. coli & $200.77 \pm 4.51$ & $0.962 \pm 0.111$ & 0.9854 \\
\hline
\end{tabular}

${ }^{\text {a Practical view }}$

BCCB $2,276.71 \pm 107.09 \quad 1.031 \pm 0.205 \quad 0.9605$

a Practical view indicated that RY2 adsorption capacity depended on the amount of chitosan included in the beads. The parameters for practical view of pristine chitosan bead are same as parameters of experimental view. 
According to table 1, the maximum RY2 uptakes ( $\mathrm{q}_{\mathrm{m}}$ ) of E. coli, CSB, and BCCB at $\mathrm{pH} 4$ were 200.77 $\pm 4.51,934.71 \pm 50.97$, and $679.13 \pm 23.76 \mathrm{mg} / \mathrm{g}$, respectively. The Langmuir constants (b) were estimated to be $0.962 \pm 0.111,1.346 \pm 0.262$, and $1.274 \pm 0.219 \mathrm{~L} / \mathrm{mg}$ for E. coli biomass, CSB, and BCCB, respectively. The RY2 uptake of CSB was about 1.4 times higher than BCCB. In addition, the RY2 uptake of BCCB which containing $70 \% \%_{\mathrm{w} / \mathrm{w}}$ of $E$. coli biomass in the bead matrix was 3.38 times higher RY2 uptake than raw E. coli biomass. The higher RY2 uptake of CS-based beads than E. coli biomass may be due to large amounts of amine groups $\left(-\mathrm{NH}_{3}{ }^{+}\right)$located in the chitosan structure which can adsorb RY2 molecules by electrostatic interaction.

\subsection{Comparison RY2 Sorption Attribution of Chitosan}

Considering the maximum RY2 uptake of $E$. coli biomass (200.77 $\pm 4.51 \mathrm{mg} / \mathrm{g}), \mathrm{CSB}(934.71 \pm 50.97 \mathrm{mg} / \mathrm{g})$ and composite ratio of E. coli biomass (70\%) and CS (30\%) in the BCCB, the expectable maximum uptake of BCCB can be estimated to be $420.05 \mathrm{mg} / \mathrm{g}$. However, the experimental maximum RY2 uptake of BCCB $(679.13 \pm 23.76 \mathrm{mg} / \mathrm{g})$ was higher than the expectable RY2 maximum uptake. For CS-based beads, it can assume that almost all the binding sites for RY2 sorption are possessed in the CS matrix. It indicates that the sorption efficiency of CS for BCCB was higher than that of CSB for RY2. Hence, comparison of the RY2 uptakes based on CS contents in CS-based beads was carried out. qkr

The practical RY2 adsorption capacity $\left(\mathrm{q}_{\mathrm{p}}\right)$ indicated the RY2 uptake by CS in the beads. Therefore, the practical RY2 uptakes of CS-based beads were calculated from the isotherm experimental data of them by following simple mass balance equation. The CS ratios in the CSB and BCCB was 1 and 0.3 , respectively.

$$
q_{p}=\frac{q}{\text { Chitosan ratio in the bead }}
$$

The comparison of practical RY2 uptakes between the CSB and BCCB are shown in Fig. 4. The maximum qp of the CSB (934.71 $\mathrm{mg} / \mathrm{g}$ ) was same as the result of isotherm for the CSB (Fig. 3). This is because the original composition of the CSB was purely

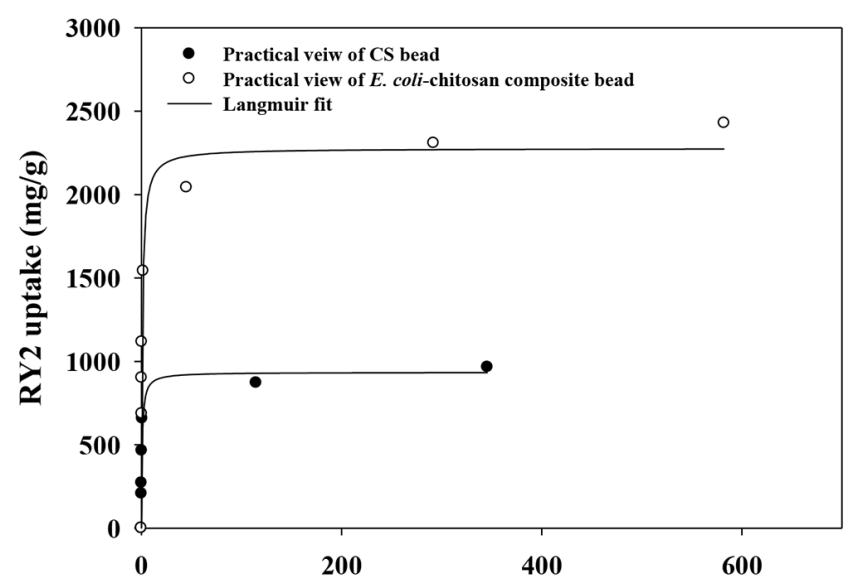

Equilibrium concentration of RY2 (mg/L)

Fig. 4. Practical RY2 sorption capacities of chitosan in the chitosan-based beads at $\mathrm{pH} 4$.
CS. However, the maximum $\mathrm{q}_{\mathrm{p}}$ value of BCCB was calculated as $2,276.71 \pm 107.09 \mathrm{mg} / \mathrm{g}$ based on the amount of CS in the bead (30\% $\%_{\mathrm{w} / \mathrm{w}}$ chitosan) by Langmuir equation, and this was 2.4 times higher than that of the CSB. It might be due to RY2 transfer interfering into the CSB by more dense structure of CSB compared to BCCB. It can be supported by SEM observation results of CSB and BCCB (Fig. 5). In the SEM observation results, it was found that the CSB shows dense and strict morphological property compared to that of BCCB. BCCB shows relatively rough surface. In addition, large pores can be found, which might be formed by mixed air bubbles during mixing of $E$. coli biomass with CS solution for bead fabrication. Although the CSB contained a lot of amine groups compared to BCCB, the rough surface and pores of the BCCB might contribute to easier and more efficient RY2 contact to the CS molecules in the BCCB. The RY2 sorption kinetic data also might support this phenomenon. The results of kinetic experiments using CSB and BCCB were displayed in Fig. 6. To detail compare of kinetics of CSB and BCCB, pseudo- $2^{\text {nd }}$ model which can represented as below was applied on the experimental kinetic data.
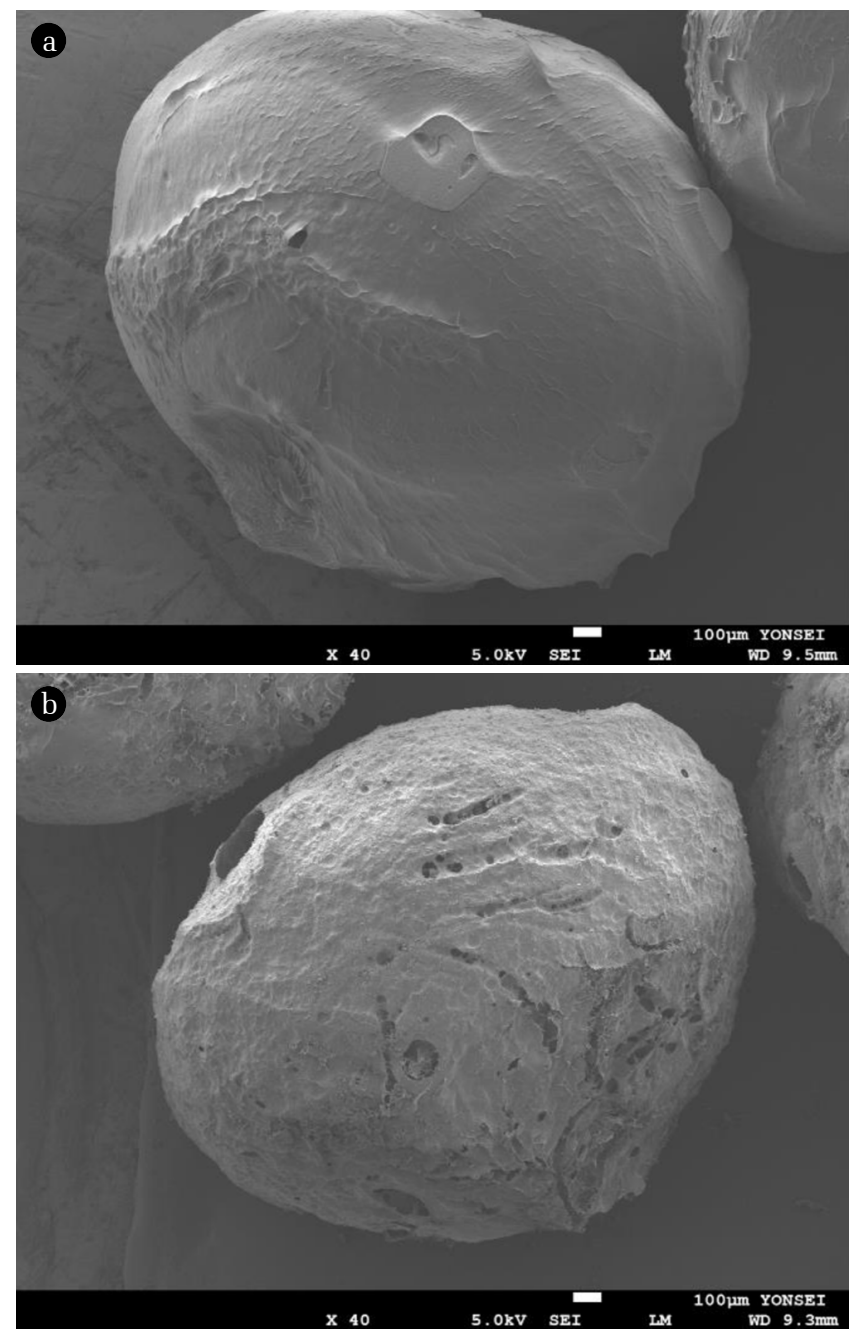

Fig. 5. SEM images of (a) CSB and (b) BCCB observed at $\times 40$ magnification. 


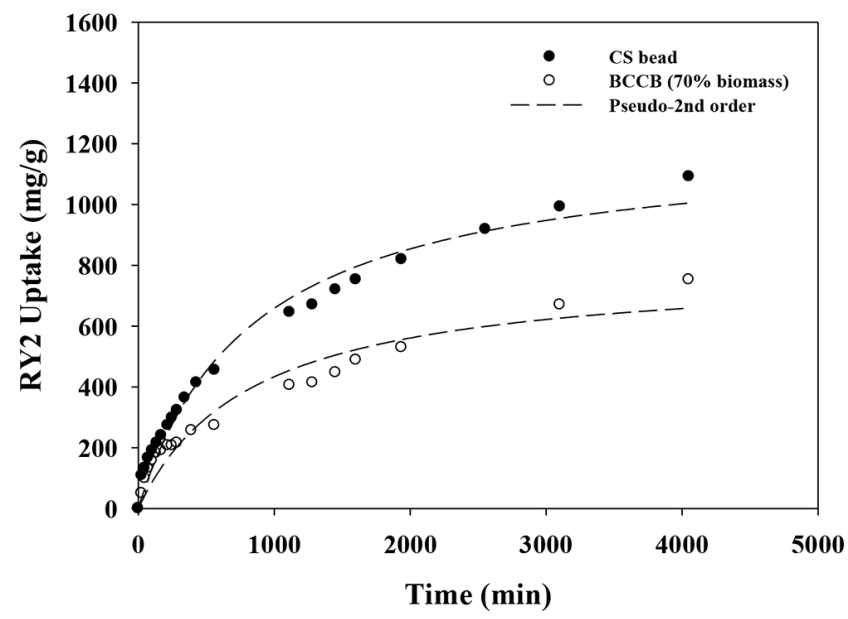

Fig. 6. RY2 sorption kinetics of CSB and BCCB at $\mathrm{pH}$ 4. The sorbent and initial RY2 concentrations for experiment were $1 \mathrm{~g} / \mathrm{L}$ and $2,021 \mathrm{mg} / \mathrm{L}$, respectively.

$$
\begin{aligned}
& \text { Pseudo }-2 \text { nd order model } \\
& q_{t}=\left(q_{e 2}^{2} \times k_{2} \times t\right) /\left(1+q_{e 2} \times k_{2} \times \mathrm{t}\right)
\end{aligned}
$$

where the $\mathrm{q}_{\mathrm{t}}$ is experimentally determined RY2 sorption capacity of sorbent at sorption time ( $\mathrm{t}, \mathrm{min})$. The terms of $\mathrm{q}_{\mathrm{e} 2}$ and $\mathrm{k}_{2}$ indicate the RY2 sorption capacities of sorbents (mg/g) at sorption equilibrium and rate constant $(\mathrm{g} / \mathrm{mg} \cdot \mathrm{min})$ calculated from pseudo- $2^{\text {nd }}$ order model, respectively. From pseudo- $2^{\text {nd }}$ order model $\left(\mathrm{R}^{2}\right.$ values for CSB and BCCB are 0.9789 and 0.9351, respectively), although the RY2 sorption capacities of CSB at equilibrium ( $\mathrm{q}_{\mathrm{e} 2}$ ) was calculated as higher value $(1,214.28 \pm 52.24 \mathrm{mg} / \mathrm{g})$ than BCCB $(794.51 \pm$ $64.16 \mathrm{mg} / \mathrm{g})$, the rate constant $\left(\mathrm{k}_{2}\right)$ of BCCB $\left((1.511 \pm 0.431) \times 10^{-6}\right.$ $\mathrm{g} / \mathrm{mg} \cdot \mathrm{min})$ was higher than that of CSB $\left((0.976 \pm 0.149) \times 10^{-6}\right.$ $\mathrm{g} / \mathrm{mg} \cdot \mathrm{min})$. This higher rate constant of BCCB might be attributed by rough and porous morphological properties of BCCB.

\subsection{Cost Effectiveness Comparison of CS-based Beads}

In conclusion, it was found that chitosan can be used more effectively for RY2 sorption process when biomass was composited in the bead. In addition, the effective usage of CS can give the cost-benefit to CS-based sorbents. The main factor of cost for making the
CS-based beads may be dependent on the amount of used CS, not $E$. coli biomass because the biomass is a waste material (zero-cost). Therefore, by blending waste $E$. coli biomass with CS, it is expected that the price of BCCB can be reduced to $30 \%$ compared to case of only CS use.

Based on the maximum sorption capacities of the sorbents, the adsorption process for RY2 treatment will require 1.4 times more BCCB than CSB when same amount of RY2 is to be treated. However, according to the amount of CS used for CS-based beads, the sorbent price of BCCB is cheaper than that of CSB. In other words, 58\% of process cost for RY2 wastewater treatment can be reduced when BCCB is used as sorbent (Table 2), and as the main cost factor for RY2 treating process is price of sorbents, this is expected to create a huge economical boost in terms of cost reduction.

\section{Conclusions}

In this study, the cost-effective sorbent prepared via blending of waste E. coli biomass and CS is suggested for removing RY2. By the SEM analysis, it was confirmed that the BCCB has more rough and porous morphological structure than the CSB. The RY2 adsorption capacities of sorbents were significantly influenced by the solution $\mathrm{pH}$. The RY2 maximum adsorption capacity of the CSB $(934.71 \pm 50.97 \mathrm{mg} / \mathrm{g})$ was higher than that of BCCB $(679.13 \pm 23.76$ $\mathrm{mg} / \mathrm{g}$ ) and $E$. coli biomass $(200.77 \pm 4.51 \mathrm{mg} / \mathrm{g}$ ) at $\mathrm{pH} 4$. However, the practical RY2 adsorption capacity of BCCB which calculation was based on amount of CS in the sorbrents was 2.1 times higher than that of the CSB. It was found that BCCB could be made cheaper than CSB from the information of bead composition ratio for CS-based beads. In addition, the cost of RY2 sorption process using BCCB is expected to be shortened by $58 \%$ compared to CSB.

\section{Nomenclature}

$$
\begin{array}{ll}
\mathrm{b} & \text { : Langmuir constant }(\mathrm{L} / \mathrm{mg}) \\
\mathrm{BCCB} & : \text { bacterial biomass-chitosan composite beads } \\
\mathrm{C}_{\mathrm{e}} & : \text { RY2 concentration }(\mathrm{mg} / \mathrm{L}) \text { at sorption equilibrium } \\
\mathrm{C}_{\mathrm{i}} \text { and } \mathrm{C}_{\mathrm{f}}: \begin{array}{l}
\text { : Initial and final concentration of RY2 in the ex- } \\
\text { perimental samples }
\end{array}
\end{array}
$$

\begin{tabular}{|c|c|c|c|c|c|c|c|}
\hline Sorbents & $\begin{array}{c}{ }^{\mathrm{a}} \text { Chitosan price } \\
\$ / \mathrm{kg}\end{array}$ & $\begin{array}{c}\text { Chitosan content } \\
\%\end{array}$ & $\begin{array}{l}{ }^{\text {b }} \text { RY2 treating } \\
\text { capacity } \\
\text { g/kg }\end{array}$ & $\begin{array}{c}{ }^{\mathrm{C}} \text { Required } \\
\text { amount of sorbent } \\
\mathrm{kg}\end{array}$ & $\begin{array}{l}{ }^{\mathrm{d}} \text { Required } \\
\text { amount of chitosan } \\
\mathrm{kg}\end{array}$ & $\begin{array}{l}{ }^{\mathrm{e}} \text { Sorbent Price } \\
\$ / \mathrm{kg}\end{array}$ & $\begin{array}{c}{ }^{\mathrm{f}} \text { Ratio of oost down } \\
\%\end{array}$ \\
\hline CSB & 17 & 100 & 934.71 & 1 & 1 & 17 & 0 \\
\hline$B C C B$ & 17 & 29.6 & 679.13 & 1.4 & 0.42 & 7.14 & 58 \\
\hline
\end{tabular}

Table 2. Cost Comparisons of Chitosan Based Beads for Treatment of RY2 Wastewater

${ }^{a}$ Average market price for bulk chitosan $(14 \sim 20 \$ / \mathrm{kg})$.

${ }^{\mathrm{b}}$ The RY2 treating capacity was estimated from the maximum capacities of CSB and BCCB.

${ }^{\mathrm{c}}$ Assuming that same amounts of RY2 were treated, required sorbent amounts of chitosan and E. coli-chitosan composite beads were calculated based on the maximum RY2 sorption capacities of CS-based beads.

${ }^{\mathrm{d}}$ The required chitosan amounts in chitosan and E. coli-chitosan composite beads were calculated by applying chitosan contents in the beads of the CS-based sorbents for treating same amounts of RY2.

${ }^{\mathrm{e}}$ The prices of sorbents were set by using the demands and average price of chitosan.

${ }^{\mathrm{f}}$ It is assumed that the main cost factor for adsorption process is sorbents prices. 


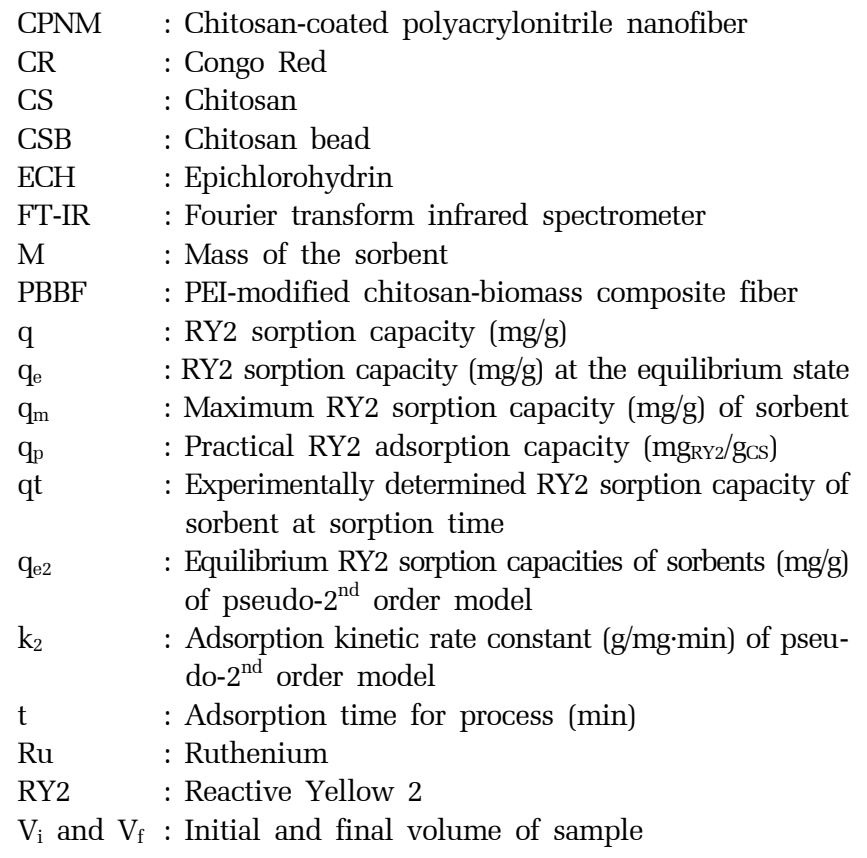

\section{Acknowledgment}

This work was supported by the National Research Foundation of Korea (NRF) funded by the Ministry of Education (NRF-2021R1I1 A1A01054658 and NRF-2021R1A6A1A10045235) grants.

\section{Author Contributions}

S. K. (Ph.D.) conducted all the experiment of the present study and manuscript preparation.

\section{References}

1. Reck IM, Paixao RM, Bergamasco R, Vieira MF, Vieira AMS. Removal of tartrazine from aqueous solutions using adsorbents based on activated carbon and Moringa oleifera seeds. J. Clean. Prod. 2018;171:85-97.

2. Elgarahy AM, Elwakeel KZ, Mohammad SH, Elshoubaky GA. A critical review of biosorption of dyes, heavy metals and metalloids from wastewater as an efficient and green process. Clean. Eng. Technol. 2021;4:100209.

3. Bello K, Sarojini BK, Narayana B, Rao A, Byrappa K. A study on adsorption behavior of newly synthesized banana pseudo-stem derived superabsorbent hydrogels for cationic and anionic dye removal from effluents. Carbohydr. polym. 2018;181:605-615.

4. Pereira L, Alves M. Dyes - environmental impact and remediation. In: Environmental protection strategies for sustainable development. Springer: 2012. p. 111-162.

5. Chicinaş RP, Bedelean H, Stefan R, Măicăneanu A. Ability of a montmorillonitic clay to interact with cationic and anionic dyes in aqueous solutions. J. Mol. Struct. 2018;1154:187-195.

6. Wang M-X, Zhang Q-L, Yao S-J. A novel biosorbent formed of marine-derived Penicillium janthinellum mycelial pellets for removing dyes from dye-containing wastewater. Chem. Eng. J. 2015;259:837-844.

7. Khadivinia E, Sharafi H, Hadi F, et al. Cadmium biosorption by a glyphosate-degrading bacterium, a novel biosorbent isolated from pesticide-contaminated agricultural soils. J. Ind. Eng. Chem. 2014;20:4304-4310.

8. Kim S, Kumar Reddy DH, Choi Y-E, Yun Y-S. Importance of the coating $\mathrm{pH}$ in fabrication of polyethylenimine-coated polysulfone-Escherichia coli composite fiber sorbent, J. Taiwan Inst. Chem. Eng. 2016;66:379-385.

9. Ramrakhiani L, Halder A, Majumder A, Mandal AK, Majumdar $\mathrm{S}$, Ghosh S. Industrial waste derived biosorbent for toxic metal remediation: mechanism studies and spent biosorbent management. Chem. Eng. J. 2017;308:1048-1064.

10. Vera LM, Bermejo D, Uguña MF, Garcia N, Flores M, González E. Fixed bed column modeling of lead(II) and cadmium(II) ions biosorption on sugarcane bagasse. Environ. Eng. Res. 2019;24: 31-37.

11. Mohapatra RK, Parhi PK, Pandey S, Bindhani BK, Thatoi H, Panda CR. Active and passive biosorption of $\mathrm{Pb}$ (II) using live and dead biomass of marine bacterium Bacillus xiamenensis PbRPSD202: Kinetics and isotherm studies. J. Environ. Manag. 2019;247:121-134.

12. Tavana M, Pahlavanzadeh H, Zarei MJ. The novel usage of dead biomass of green algae of Schizomeris leibleinii for biosorption of copper(II) from aqueous solutions: Equilibrium, kinetics and thermodynamics. J. Environ. Chem. Eng. 2020;8: 104272.

13. Khawar A, Aslam Z, Javed S, Abbas A. Pb (II) biosorption using DAP/EDTA-modified biopolymer (Chitosan). Chem. Eng. Commun. 2018;205:1555-1567.

14. Ahmad A, Bhat A, Buang A. Biosorption of transition metals by freely suspended and Ca-alginate immobilised with Chlorella vulgaris: kinetic and equilibrium modeling. J. Clean. Prod. 2018;171:1361-1375.

15. Wan M-W, Kan C-C, Rogel BD, Dalida MLP. Adsorption of copper (II) and lead (II) ions from aqueous solution on chitosan-coated sand. Carbohydr. Polym. 2010;80:891-899.

16. Lou T, Yan X, Wang X. Chitosan coated polyacrylonitrile nanofibrous mat for dye adsorption. Inter. J. Biol. Macromol. 2019;135:919-925.

17. Uzun I. Kinetics of the adsorption of reactive dyes by chitosan. Dyes Pigment. 2006;70:76-83.

18. Wang Y, Wang H, Peng H, Wang Z, Wu J, Liu Z. Dye Adsorption from Aqueous Solution by Cellulose/Chitosan Composite: Equilibrium, Kinetics, and Thermodynamics. Fibers Polym. 2018;19:340-349.

19. Kwak IS, Won SW, Chung YS, Yun Y-S. Ruthenium recovery from acetic acid waste water through sorption with bacterial biosorbent fibers. Bioresour. Technol. 2013;128:30-35.

20. Kim S, Park TH, Lee JB, Kim HS, Choi Y-E. Phosphorus adsorption behavior of industrial waste biomass-based adsorbent, esterified polyethylenimine-coated polysulfone-Escherichia coli biomass composite fibers in aqueous solution. J. Hazard. Mater. 
2020;400:123217.

21. Kim S, Won SW, Cho C-W, Yun Y-S. Valorization of Escherichia coli waste biomass as a biosorbent for removing reactive dyes from aqueous solutions. Desalin. Water Treat. 2016;57:20084-20090.

22. Ziarani GM, Gholamzadeh P, Badiei A, Vavsari VF. The role of pyruvic acid as starting material in some organic reactions in the presence of SBA-Pr-SO $3 \mathrm{H}$ nanocatalyst. Res. Chem. Intermed. 2018;44:277-288.

23. Khanage S, Mohite P, Pandhare R. Synthesis and Antimicrobial Evaluation of 4-(4, 5-diphenyl-1H-imidazole-2-yl)-2-methoxyphenyl-N-substituted aminoacetate Derivatives. Anal. Chem. Lett. 2020;10:517-523.

24. Agatonovic-Kustrin S, Ristivojevic P, Gegechkori V, Litvinova TM, Morton DW. Essential oil quality and purity evaluation via $\mathrm{ft}$-ir spectroscopy and pattern recognition techniques. Appl. Sci. 2020;10:7294.

25. Naeimi A, Khoshkam S, Eslaminejad T. Natural cellulose fibers from Quinoa wastes reinforced carbon nanotube/ZnO bio-nanocomposite as a novel recyclable catalyst for oxidation reaction. Polym. Bull. 2021:1-14.

26. Lin H, Bean S, Tilley M, Peiris K, Brabec D. Qualitative and Quantitative Analysis of Sorghum Grain Composition Including Protein and Tannins Using ATR-FTIR Spectroscopy. Food Anal. Method. 2021;14:268-279.

27. Chanphai P, Tajmir-Riahi H. Locating the binding sites of citric acid and gallic acid on milk $\beta$-lactoglobulin. J. Biomol. Struct. Dyn. 2021;39:5160-5165.

28. Chouaya S, Abbassi M, Younes R, Zoulalian A. Scrap tires pyrolysis: Product yields, properties and chemical compositions of pyrolytic oil, Russian J. Appl. Chem. 2018;91:1603-1611.

29. Patle TK, Shrivas K, Kurrey R, Upadhyay S, Jangde R, Chauhan R. Phytochemical screening and determination of phenolics and flavonoids in Dillenia pentagyna using UV-vis and FTIR spectroscopy. Spectrochim. Acta Part A Mol. Biomol. Spectroscopy. 2020;242:118717.

30. Huang J, Bekiaris G, Fitamo T, Scheutz C, Bruun S. Prediction of biochemical methane potential of urban organic waste using Fourier transform mid-infrared photoacoustic spectroscopy and multivariate analysis. Sci. Total Environ. 2021;790:147959.

31. Xu D, Yu K, Qian K. Thermal degradation study of rigid polyurethane foams containing tris (1-chloro-2-propyl) phosphate and modified aramid fiber. Polym. Test. 2018;67:159-168.
32. Trang NTT, Chinh NT, Mai TT, Trung TH, Hoang T. Investigation of effect of polyethylene oxide on properties and morphology of polylactic acid/chitosan/quinine composites. Vietnam J. Chem. 2019;57:52-56.

33. Anush S, Vishalakshi B, Kalluraya B, Manju N. Synthesis of pyrazole-based Schiff bases of Chitosan: Evaluation of antimicrobial activity, Inter. J. Biol. Macromol. 2018;119:446-452.

34. Sankarganesh M, Raja JD, Revathi N, Solomon RV, Kumar RS. Gold (III) complex from pyrimidine and morpholine analogue Schiff base ligand: synthesis, characterization, DFT, TDDFT, catalytic, anticancer, molecular modeling with DNA and BSA and DNA binding studies. J Mol. Liq. 2019;294:111655.

35. Raeiatbina P, Açıelb YS. Removal of tetracycline by magnetic chitosan nanoparticles from medical wastewaters. Desalin. Water Treat. 2017;73:380-388.

36. Machado W, Franchini JC, de Fátima Guimarães M, Tavares Filho J. Spectroscopic characterization of humic and fulvic acids in soil aggregates, Brazil. Heliyon 2020;6:e04078.

37. Ngah WW, Fatinathan S. Pb (II) biosorption using chitosan and chitosan derivatives beads: Equilibrium, ion exchange and mechanism studies. J. Environ. Sci. 2010;22:338-346.

38. Bilas R, Sriram K, Maheswari PU, Begum KMS. Highly biocompatible chitosan with super paramagnetic calcium ferrite $\left(\mathrm{CaFe}_{2} \mathrm{O}_{4}\right)$ nanoparticle for the release of ampicillin, Inter. J. Biol. Macromol. 2017;97:513-525.

39. Ramrakhiani L, Majumder R, Khowala S. Removal of hexavalent chromium by heat inactivated fungal biomass of Termitomyces clypeatus: Surface characterization and mechanism of biosorption, Chem. Eng. J. 2011;171:1060-1068.

40. Yun Y-S, Park D, Park JM, Volesky B. Biosorption of trivalent chromium on the brown seaweed biomass. Environ. Sci. Technol. 2001;35:4353-4358.

41. Won SW, Choi SB, Yun Y-S. Binding sites and mechanisms of cadmium to the dried sewage sludge biomass. Chemosphere 2013;93(1):146-151.

42. Mourya V, Inamdar NN, Tiwari A. Carboxymethyl chitosan and its applications, Adv. Mater. Lett. 2010;1:11-33.

43. Langmuir I. The adsorption of gases on plane surfaces of glass, mica and platinum. J. American Chem. Soc. 1918;40:1361-1403.

44. Won SW, Yun Y-S. Biosorptive removal of Reactive Yellow 2 using waste biomass from lysine fermentation process. Dyes Pigment. 2008;76:502-507. 